\title{
Identifying and ranking the indicators of crisis management with using VIKOR method
}

\begin{abstract}
Abotaleb Khedmati ${ }^{a^{*}}$
${ }^{a}$ Department of Management, Research Institute of Howza and University, Qom, Iran

CHRON I C L E A B S T RACT

Article history:

Received January 5, 2016

Received in revised format August 2, 2016

Accepted September 28, 2016

Available online

September 29, 2016

Keywords:

Crisis Management

Crisis Management Indicators

VIKOR Method

Vast changes and increase in global events have caused a crisis among public and private organizations. If organizations cannot manage the created crisis, they might be damaged widely. Lack of readiness and inappropriate management of crisis might even lead to the destruction of the organizations. Therefore, crisis management prepares the conditions to reduce the destructive effects caused by crisis. Having crisis management in organization requires expansion of various indicators that implementing and operating each of these indicators increase the organization capability to confront with crisis. In the present study, identifying and ranking indicators of crisis management have been considered. The primary results indicate that 12 indexes have been identified for crisis management. In addition, the results, according to experts' ideas, led to elimination of two indicators and 10 indexes were finalized. Then, using VIKOR method, the final indicators were ranked. The results of ranking indicated that three indexes of appropriate management style, management of human resource and responding speed, as well as crisis confrontation regarding cost, time were at the best to be implemented in the organization.
\end{abstract}

\section{Introduction}

For years, human life has always paved with difficulties and confrontations. Gradually, the social dimension and system-orientation of life have been increased; cooperation and relations within the community in the form of interests, social and personal interests have taken more concrete form. As a result, some boundaries have been created in social organization and in the domain of group benefits and social and political competitions. Consequently, the hardships have taken newer and more complicated forms. In the new era and blossoming of civilization at the same time with the raise in the civil awareness levels increasing demands and social needs, the difficulties in the form of various "crises" have pervaded the life and political life of communities. They have created restrictions and requirements in different fields of social relations as well as in the structure of decision-making system. In fact, nowadays, no political and social systems can be immune to the crisis and its short and long- 
term consequences. Crises are integrated part of life and are the prerequisites of political development, especially in "transitional societies". Crises are potentially a formation ground for threats and opportunities that depending on the type, severity and extent of the environmental crisis can make the difficult and precarious position for the political system and the ruling elite. Increasing structural and applied capacity of the political system to respond to the needs and requirements of people is a fair and effective element for forming resistant structures of people dealing with the crisis.

The important political, economic, social, geographical and human events of the recent decades of the world indicate that human communities have been constantly exposed to natural disasters or humans' destructive desires leading to various crises. There is not a single day that the news concerning small and big crises happening throughout the world would not be broadcasted via media. Such crises might continue to threaten foreign and domestic benefits of societies or validity of a great organization. Therefore, it must be mentioned that crisis has become an integral and natural section of modern organizations and communities. Crises are not considered as abnormal, rare and haphazard events for global community, but it has penetrated deep into the modern societies. All organizations are effected by the small and big crises day in, day out. Therefore, managers of organizations must always be prepared to confront with crises and find a solution to prevent or reduce the effects of them on their own organizations. They must comprehend that the organizations managed by them must be immune to crises as much as possible. If managers are constantly worried about the economic and organizational crises, they must always been wondering about how to save themselves and their organizations from the vortex of the crisis, so that the less possible damage will care for their organization. It must not be forgotten that most of big crises that have forced many of the world's economic giants into bankruptcy have not occurred haphazardly and suddenly.

Controlling the crisis based on a system-oriented and integrated thinking in terms of crisis management is a strategic requirement that is the consensus of all the scholars and experts in strategic security and political issues. In addition, they emphasize on efforts by governments to invest heavily in the development of the management system. Crisis management is the subject of in different spheres of modern societies and organizations, as one the main elements of modern society, are not exceptions. Successful and efficient managers try to avoid destructive effects and perilous waves of crises and unpredicted issue by using organizational crisis management findings. The results of previous studies show that although Iran is located in a region that is exposed to unpredicted political, economic and social events, and the possibility of creation of crisis in the total structure of system and also in active organizations structures, crisis management and its indicators have not been studied by its scholars and researchers. A few studies have been conducted regarding this subject. Therefore, in the present study, due to the importance of crisis management and identification of crisis management indicators, identifying and ranking the indicators of crisis management have been reviewed.

\section{Literature Review}

\subsection{Concepts and theories}

\subsubsection{Definition of crisis}

Crisis equals to the Latin term of "krisis" and its English equivalent is "crisis". Literally, it has been applied in various meanings; some have used crisis as an equivalent for pressure, anxiety, milestone, tragedy and violence. Others have defined crisis as a synonym for disintegration, chaos, fragility more than usual, threatening the values, socio-political instability and military conflict (Fink, 1986). In medical science, crisis is defined as "a milestone in the course of the disease, when it turns out the patient will survive or will die" (Webster dictionary). The concept of crisis can mean as deviation form general balance of organization relation with surrounding. Alternatively, it can be a definition of environmental feature that the organization is obliged to be constantly aware of. In each of the 
perspectives, performing critical issues in a strategic management perspective are best understood (Booth, 2015). Some have defined crisis as a potential and actual presence of a situation that can be used in internal or external levels to expose a state or a country with a greater risk, such as the change in government, the coup and civil war (Pearson \& Clair, 1998). Crisis is a situation that destroys the discipline of the main system or some parts of secondary systems and disturbs its stability. In other words, from the systematic viewpoints, it is a severe stroke to the international system that makes it lose its balance (Kazemi, 2013).

\subsubsection{Features of crisis}

Some of the main features of crisis are the uncertainty of the causing factors, uncertainty of the effects and consequences, and ways to solve it; In addition, decisions related to the crisis must be taken as soon as possible. A point that must not be ignored is that crises do not appear off-hand and they often have alerting signals. Therefore, managers must predict crises according to the signals and plan to prevent or fight with them prior to occurring. Identification of features, indicators and signals of crisis is urgent and essential. It will also help managers of organization differentiate normal issues form crises and apply measures to prevent and control the crisis. In addition, by accurate understanding of the basic components of the crisis, they must choose a correct path to confront the crisis and apply effective methods of confrontation with crisis. Some of scholars mention features and characteristics of crises as the following according to psychological and sociological studies:

1. A critical situation is an acute and short-term situation, although its length is always uncertain.

2. Crisis creates pathological behavior that is more pathological: such as feelings of inadequacy or searching for a false guilty.

3. The crisis threatens the goals of the parties involved.

4. Crisis is a relative thing; i.e., what is the crisis for a party or ... may not be seen as a crisis to others.

5. Crisis causes tension in the body (organism).

6. Crises are often unpredictable.

7. Crises have devastating effects.

8. Nature and consequences of the crisis are long and amortizing.

9. in critical condition, usually decision-making is under dire conditions, limited time, and incomplete information required by decision-makers.

\subsubsection{Types of crisis}

To identify and segregate the crises, it is better to classify them and consider some bases for their segregation.

\section{Classification of crises regarding them being sudden or gradual}

Some of the crises happen suddenly and at once. In addition, they have sudden effects on both internal and external environment of organization. These types of crises are called sudden crises. In contract, there are gradual crises that begin with a series of chaotic issues; enhance by time passage; continue to a threshold; and then emerge. To compare sudden and gradual crises, six key features can be utilized. Sudden crises are created very fast; have little capability of being predicted; are rather clear and distinct; start with a clear event at once; happen at the fixed time; and are resulted from the lack of compatibility of organization with one or a few aspects of environmental aspects. In contrast, gradual crises are created gradually and cumulatively; are highly predictable; are not clear and distinct; their start point is from a threshold level; the probabilities of their happening are increased by passage of time; and are created from the lack of compatibility of organization with some aspects of environment. 
Classification of the crisis from the perspective of "Parsons" (Parsons, 1996):

Urgent crises: they do not have any previous alerting signals and organizations are not able to study them and plan to expulse them.

The crises that appear gradually: they are created slowly; they can be stopped or limited through organizational measures.

Continuous crises: they continue for weeks, months or even years. Strategies to confront such crises in different conditions depend on time pressures, the extent of control and a greatness of the events

\section{Crisis classification according to perspective of "Mitroff" (Mitroff, 2004)}

He uses two spectra to classify the crises. One spectrum determines crises to be internal or external. It shows whether the crisis happens inside or outside of the organization. Another spectrum indicates the crises to be technical or social. The horizontal axis differentiates the internal and external crises and the vertical axis segregates them from the perspective of being technical or economic in contrast with being social or organizational; therefore, he distinguished four different conditions.

\subsubsection{Crisis management}

Crisis always has negative effects and consequences as well as irreparable damages and costs; therefore, crisis management and planning to control its negative effects and consequences and costs is one the most fundamental and important duties of managers in an organization. Crisis management means logical confrontation with crisis, so that it leads to control its negative effects and consequences and reversing crisis conditions to normal condition. To manage crisis and logical confrontation with it at the three levels of before crisis, during crisis and after crisis, a series of planned actions, with the aim of preventing or controlling and eliminating the effects of the crisis and returning to the situation before the crisis must be taken. Crises happen very fast; spread in a short time; and affect various domains. Therefore, if they are not managed logically and correctly, it might question the existence of organization. Some of scholars have defined crisis management as a strategic measure, in which internal and external environments of a crisis will be analyzed; the required knowledge will be obtained; and strategic path will be established; and some strategies will be created that assist elites to achieve the determined goals and worthy and necessary measure.

\subsubsection{Crisis management approaches}

Crisis management is creation of a framework to guide, control and arrange appropriate reaction to the crisis. There are two approaches and perspective about crisis management. The first one is based on the prevention of crisis and it believes that prevention is better than cure; therefore, formation of crisis management before the crisis is urgent, because it is possible that crisis happens in each organization. In order to prevent the crisis, confront with crisis making factors, and control its dimensions, crisis management must be formed. The second approach is based on the management of crisis after its occurrence. According to this approach, when an event happens, it must be clarified that the event is a normal event and issue, or it is capable of becoming a crisis. If it is recognized that the event is a normal and common issue, it must be dealt with as normal events. However, if it is diagnosed to have the capability of becoming a crisis, crisis managers should analyze the accurate nature and limits of the

event using their entire ability and capability, and act by applying crisis management and deal with the event. 


\subsubsection{Levels of crisis management}

In most patterns of crisis management, crisis levels are divided into three levels of before, during and after the crisis. Each of these requires their own special management and effect on the management of the level after them.

\section{A) The level before crisis}

At this stage, managers are expected to predict various crises related to their working domain. To do so, managers need strong information systems and environmental monitoring. In addition, managers should think about prevention of the crises occurrences, because many crises can be avoided or reduced in severity by prevention. It is logical that despite preventive and predicting measures, manager should be always ready to deal with various crises, because, as mentioned earlier, sometimes crises take place whether wanted or not.

\section{B) The level during crisis}

At this stage, manager is expected to apply alerting systems and use information centers and mass media to warn society about the possible risks. In addition, it is expected that manager provides the necessary measures aimed at hedging as far as possible. In the first hours of crisis, the primary estimation of the level and severity of crisis must be provided. Moreover, according to this primary evaluation, mobilization of all resources, both human and non-human, must be provided.

\section{C) The level after crisis}

The stage that commences after controlling the crisis applies some measures that lead to normalizing the condition. The first step and measure to reconstruct is clearing environment of any signs of crisis. This level is also called the level of repair, improvement, rehabilitation and redevelopment. At this stage, like a learning organization, by creating knowledge management system, crisis management experiences can be recorded for possible future uses and crisis management system can be analyzed regarding pathology.

\subsection{Research Background}

Fahmideh Modami and Hatami Nejad (2014) tried to identify crisis management indicators in city with the approach of prevention and readiness. In the study, due to limitation in previous studies, data were collected through library information, articles, translation of books, field visits, as well as documents, reports and scientific sites and documents related to crisis management and urban crises. Then, through the designed questionnaires, interviews and questions from the experts in Mashhad city, the indicators were identified and related analyses were conducted. The population of the study included 75 experts in the domain of urban crisis management. The results indicate how effective crisis management indicators can be in planning. In addition, natural disasters, the death toll and vulnerability are higher in developing countries in comparison with developed countries. Planning and prioritizing indexes in urban crisis management can be helpful. The focus of the study is on planning in management of disasters.

Pourmousavi et al. (2015) reviewed realization of the indicators of crisis management in detailed plan of 20th District of Tehran. The study is descriptive-analytical and is applied regarding purpose. The population of the study includes 217 skilled experts of urban planning and authorities of detailed planning in Tehran. The findings show that the 20th district is being threatened by eight natural risks and 16 human risk making focus, among which presence of rusty and dense texture, transmission of high voltage power networks and sewage networks make the most threat. The results indicate that crisis 
management indicators in the detailed plan with the scales of low and very low have been considered very much in the ideas of subjects and this much attention is significant. Therefore, the 20th district of Tehran is intensely affected by crisis management indicators and the detailed plan and guide to the development of city do not pay enough attention to it.

Kazemi (2013) examined crisis management in state-run organizations. His studies reveal that management of organization and resiliency of human resources are two vital factors during the crisis in the organization. Absence of such factors can increase the damages of crisis in the organization. Wang et al. (2009) reviewed the strategic role of human resource management in increasing the ability of crisis management in the organization. They examined 125 enterprises in Taiwan and found out that among them, the enterprises that have stronger and more efficient human recourse management strategy have better ability in crisis management. In addition, the effects of crisis in their organizations were less in comparison with others.

\subsection{Indicators of crisis management}

After the conducted reviews and according to researchers, the following indicators are identified as the indexes of crisis management:

1. Resilience of organization

2. Human Resource Management

3. Appropriate management style

4. Financial resources

5. Support

6. Communication

7. Organizational flexibility

8. Readiness of system against crisis

9. Learning from the results

10. Speed of responding and coping with crisis

11. Ability of the system retrieval after the crisis

12. Integrity of units

\section{Research Method}

The present study is descriptive-survey regarding data collection. It is descriptive because the findings are described as they have been collected without any manipulation. It is survey because the required data are collected through questionnaires.

\subsection{Focused Group}

In order to screen and rank identified factors and to determine the indicators of crisis management, the expert opinions of 25 experts and specialists who were active in the field of crisis management in the organization of crisis management, Tehran Municipality and military institutions, as well as professors in the field of crisis management have been used. These people have been selected judgmentally and non- randomly. It means that the people are selected by previous knowledge and based on their experience and information about privatization. Among these people, 17 of them have Ph.D, and eight hold master degree. In addition, six of them have experience of over 30 years, 15 people have more than 20 years of experience, and four of them have more than 10 years of experience.

\subsection{Methods and tools of data collection and analysis}

At first, indexes of crisis management were collected using library studies. Then, based on VIKOR method (Hwang \& Yoon, 1981), the especial questionnaire of this method including weighing the indexes based on the selected criteria was used. 


\subsection{Analysis method}

The term VIKOR is retrieved from the Serbian word of multi-criteria optimization and compromised solution (Amiri et al., 2011). The above method focuses on ranking and selecting a set of options in the presence of contradictory criteria. The criterion of ranking options in this method is based on how close the ideal solution is. In this method, in order to rank and find the best option, the concept of compromise between distances of options with the best option is used, and that is why it is categorized into compromise planning (Moradi et al., 2012). Using this method of analysis, indicators of crisis management indicators are ranked simply, but remarkably and determinably. To calculate the importance of each of the indicators of crisis management by using the VIKOR method, the following relation has been used:

$$
L p_{i}=\left\{\sum_{j=1}^{n}\left[w_{i}\left(f_{j}^{*}-f_{i j}\right) /\left(f^{*}-f_{j}^{-}\right)\right]^{p}\right\}^{1 / p}
$$

where $f_{i j}=$ alternatives $w_{i}=$ weighting of criteria $P=$ index VIKOR $=f_{j}^{*}$ Maximum reagents $f_{j}^{-}=$ least reagents

Finally, to find the final index of development for each unit, the following relationship has been used:

The first level: data collection and matrix formation;

The second level: normalization of data: that in this level, after exponentiation of matrix numbers, we divide values of each of the criteria into Total Square of the same criteria. In this method, to normalize data, linear normalizer is used. In this model, the best option is the option that has allocated the least numerical value among the alternatives to it; and has allocated the title of ideal among the alternatives to it.

The third level: Involving coefficient value of the effect of each of measures in normalized weight The forth level: Calculation of the minimum and maximum of each criterion and calculation of the amount of difference between them,

The fifth level: obtaining the maximum distance between each of the numbers calculated in the third stage, then,

The sixth level: calculation of the $\mathrm{i}^{\text {th }}$ distance from positive ideal option (the best compound).

Calculation of the $\mathrm{Si}$ value is as follows,

$$
S_{i}=\sum_{i=1}^{n}\left[w_{i}\left(f_{j}^{*}-f_{i j}\right) /\left(f^{*}-f_{j}^{-}\right)\right]
$$

where $S_{i}$ represents the ith distance from positive ideal option

The seventh level: calculation of the $\mathrm{i}^{\text {th }}$ distance from negative ideal option (the worst compound).

$$
R_{i}=\max \left[w_{i}\left(f_{j}^{*}-f_{i j}\right) /\left(f^{*}-f_{j}^{-}\right)\right]
$$

The eighth level: the last level in VIKOR model is calculation of VIKOR value or so-called Qi. $\mathrm{V}$ - The constant value

$$
Q=V\left[\frac{S_{I}-S^{*}}{S^{-}-S^{*}}\right]+(1-V)\left[\frac{R_{I}-R^{*}}{R^{-}-R^{*}}\right]
$$

After applying VIKOR formula, some numbers will be obtained that are from 0 to 1 . Each of the criteria with the least point is the best or the most efficient option. In addition, the maximum gained weight indicates the undesirability of the options in the area. 


\section{Research Findings}

In the following, first, the identified indexes are screened according to the experts' ideas. Then, using VIKOR method, the indicators are ranked to prepare a list of the most important indexes for crisis managers.

\subsection{Final indicators}

To determine the final indexes, the experts' ideas have been used. Thus, the identified indexes were sent to experts in a questionnaire, and they were asked to comment on the appropriateness of indicators to measure crisis management from fully inappropriate to fully appropriate. Geometric mean method was used to calculate the resultant of Comments. The indexes with the experts' comments average of more than 3 are selected as the final indexes and others are deleted.

Table 1

Final indexes according to experts' comments

\begin{tabular}{lcc}
\hline Indexes & average & experts' comments \\
\hline 1. Resilience of organization & 2.173 & Rejected \\
2. Human Resource Management & 4.308 & Confirmed \\
3. Appropriate management style & 3.841 & Confirmed \\
4. Financial resources & 4.227 & Confirmed \\
5. Support & 2.072 & Rejected \\
6. Communication & 3.591 & Confirmed \\
7. Organizational flexibility & 3.774 & Confirmed \\
8. Readiness of system against crisis & 3.862 & Confirmed \\
9. Learning from the results & 3.074 & Confirmed \\
10. Speed of responding and coping with crisis & 3.941 & Confirmed \\
11. Ability of the system retrieval after the crisis & 3.194 & Confirmed \\
12. Integrity of units & 3.829 & Confirmed \\
\hline
\end{tabular}

According to the results of experts' comments, it is determined that two indexes of resiliency and support of organization are not categorized as appropriate indexes in the idea of experts in the present study. Therefore, they are deleted from the model of indexes of crisis management of organizations. Consequently, 10 indexes will be ranked according to VIKOR method

\subsection{Indicators' ranking}

\subsubsection{Ranking criteria of evaluation of the indicators}

The previous studies and reviews of experts' comments indicate that 3 criteria are more important than the other ones. They are cost, time and the possibility to develop indicators of crisis management in the organization. Prior to ranking indexes, criteria must be ranked and weight of each of them must be placed in VIKOR model to be used for weighted matrix.

Table 2

The results of paired comparisons for weighting the criteria

\begin{tabular}{cccccc}
\hline & Possibility & Time & Cost & Final Weight & Rank the criteria \\
\hline Possibility & 0.142 & 0.111 & 0.157 & 0.137 & 3 \\
Time & 0.285 & 0.222 & 0.210 & 0.239 & 2 \\
Cost & 0.571 & 0.666 & 0.631 & 0.623 & 1 \\
\hline
\end{tabular}

Inconsistency ratio: 0.007 
According to the results, it is determined that the cost of establishment of indicators is more important than other criteria. In addition, two criteria of time and the possibility are at the second and third positions. Considering the results about weights of criteria, in the following, the indicators will be ranked.

\subsubsection{Ranking indicators}

To rank indicators of crisis management according to the selected criteria, a questionnaire was given to experts and they were asked to determine the position of each of the indexes of crisis management based on the criteria. The results will be represented in the following:

Table 3

Average of comments obtained from the experts

\begin{tabular}{lccc}
\hline & \multicolumn{3}{c}{ Criteria } \\
\cline { 2 - 4 } Indicators of crisis management & Possibility & Time & Cost \\
\hline Human Resource Management & 3.17 & 2.94 & 3.55 \\
Appropriate management style & 3.97 & 1.84 & 2.16 \\
Financial resources & 2.19 & 4.96 & 5.99 \\
Communication & 2.59 & 3.69 & 5.19 \\
Organizational flexibility & 1.06 & 3.15 & 4.78 \\
Readiness of system against crisis & 2.75 & 2.78 & 3.56 \\
Learning from the results & 2.14 & 1.06 & 2.67 \\
Speed of responding and coping with crisis & 2.77 & 2.14 & 3.17 \\
Ability of the system retrieval after the crisis & 1.05 & 2.86 & 3.04 \\
Integrity of units & 1.62 & 3.77 & 3.63 \\
\hline
\end{tabular}

After averaging, the collected data were entered to the designed software in excel to calculate VIKOR. The ideal point and anti- ideal point were calculated because of the criteria.

\section{Table 4}

Ideal point and anti- ideal point because of the quality of criteria

\begin{tabular}{lccc}
\hline Criteria & Possibility & Time & Cost \\
\hline Ideal point & 3.97 & 1.06 & 2.16 \\
Anti- ideal point & 1.05 & 4.96 & 5.99 \\
\hline
\end{tabular}

Then, the amount of minimum coverage for anti- ideal are calculated and the results are given in Table 5 as follows,

\section{Table 5}

Minimum coverage for anti- ideal

\begin{tabular}{|c|c|c|c|}
\hline \multirow[b]{2}{*}{ Indicators of crisis management } & \multicolumn{3}{|c|}{ criteria } \\
\hline & Possibility & Time & Cost \\
\hline Human Resource Management & -2.12 & 2.02 & 2.44 \\
\hline Appropriate management style & -2.92 & 3.12 & 3.83 \\
\hline Financial resources & -1.14 & 0 & 0 \\
\hline Communication & -1.54 & 1.27 & 0.8 \\
\hline Organizational flexibility & -0.01 & 1.81 & 1.21 \\
\hline Readiness of system against crisis & -1.7 & 2.18 & 2.43 \\
\hline Learning from the results & -1.09 & 3.9 & 3.32 \\
\hline Speed of responding and coping with crisis & -1.72 & 2.82 & 2.82 \\
\hline Ability of the system retrieval after the crisis & 0 & 2.1 & 2.95 \\
\hline Integrity of units & -0.57 & 1.19 & 2.36 \\
\hline
\end{tabular}


Then, the weighted normal matrix is formed:

Table 6

Weighted normal matrix

\begin{tabular}{lccc}
\hline & \multicolumn{3}{c}{ criteria } \\
\cline { 2 - 4 } Indicators of crisis management & Possibility & Time & Cost \\
\hline Human Resource Management & -0.43226 & 0.278933 & 0.310185 \\
Appropriate management style & -0.59538 & 0.430828 & 0.486888 \\
Financial resources & -0.23244 & 0 & 0 \\
Communication & -0.314 & 0.175369 & 0.1017 \\
Organizational flexibility & -0.00204 & 0.249935 & 0.153821 \\
Readiness of system against crisis & -0.34662 & 0.301027 & 0.308913 \\
Learning from the results & -0.22225 & 0.538535 & 0.422055 \\
Speed of responding and coping with crisis & -0.3507 & 0.389402 & 0.358492 \\
Ability of the system retrieval after the crisis & 0 & 0.28998 & 0.375018 \\
Integrity of units & -0.11622 & 0.164322 & 0.300015 \\
\hline
\end{tabular}

After calculation of weighted normal matrix, it is turn of calculation of positive and negative criteria of the model. These two criteria are represented in the following table:

Table 7

Positive and negative criteria

\begin{tabular}{rccc}
\hline & Possibility & Time & Cost \\
\hline Positive criteria & 0.000 & 0.000 & 0.000 \\
Negative criteria & -0.595 & 0.539 & 0.487 \\
\hline
\end{tabular}

After calculation of positive and negative criteria, distance of each of the options from positive and negative criteria is calculated

Table 8

Distance of each of the options from positive and negative criteria

\begin{tabular}{lccc} 
& & Criteria \\
Indicators of crisis management & Possibility & Time & Cost \\
\hline Human Resource Management & 0.338 & 0.083 & 0.176 \\
Appropriate management style & 0.466 & 0.129 & 0.277 \\
Financial resources & 0.182 & 0.000 & 0.000 \\
Communication & 0.246 & 0.052 & 0.058 \\
Organizational flexibility & 0.002 & 0.075 & 0.088 \\
Readiness of system against crisis & 0.271 & 0.090 & 0.176 \\
Learning from the results & 0.174 & 0.161 & 0.240 \\
Speed of responding and coping with crisis & 0.274 & 0.116 & 0.204 \\
Ability of the system retrieval after the crisis & 0.000 & 0.087 & 0.213 \\
Integrity of units & 0.091 & 0.049 & 0.171 \\
\hline
\end{tabular}

After calculation of positive and negative criteria, utility value (S) and regret value (R) are calculated. 
Table 9

Utility values and the maximum and minimum values of regret

\begin{tabular}{lcc}
\hline Indicators of crisis management & $\mathrm{Si}$ & $\mathrm{Ri}$ \\
\hline Human Resource Management & 0.598 & 0.338 \\
Appropriate management style & 0.872 & 0.466 \\
Financial resources & 0.182 & 0.182 \\
Communication & 0.356 & 0.246 \\
Organizational flexibility & 0.164 & 0.088 \\
Readiness of system against crisis & 0.537 & 0.271 \\
Learning from the results & 0.575 & 0.240 \\
Speed of responding and coping with crisis & 0.595 & 0.274 \\
Ability of the system retrieval after the crisis & 0.300 & 0.213 \\
Integrity of units & 0.311 & 0.171 \\
\hline
\end{tabular}

Table 10

Maximum and minimum values of utility and regret

\begin{tabular}{cccc}
\hline $\mathrm{R}^{*}$ & 0.088 & $\mathrm{~S}^{*}$ & 0.164 \\
$\mathrm{R}-$ & 0.466 & $\mathrm{~S}-$ & 0.872 \\
\hline
\end{tabular}

Then, the weight calculation and final rank of each index have been done:

\section{Table 11}

Weight and final rank of each index of crisis management according to Q value

\begin{tabular}{lcc}
\hline Indicators of crisis management & Qi & Final rank \\
\hline Human Resource Management & 0.638 & 2 \\
Appropriate management style & 1.000 & 1 \\
Financial resources & 0.138 & 9 \\
Communication & 0.345 & 6 \\
Organizational flexibility & 0.000 & 10 \\
Readiness of system against crisis & 0.506 & 4 \\
Learning from the results & 0.492 & 5 \\
Speed of responding and coping with crisis & 0.551 & 3 \\
Ability of the system retrieval after the crisis & 0.262 & 7 \\
Integrity of units & 0.214 & 8 \\
\hline
\end{tabular}

The results indicate that proper management style, human resource management and quick responding and dealing with crisis are the three indexes that can be implemented in the organizations cheaper, faster and easier than the other indexes. In addition, they can help organizations in crisis management. Also, indexes of funding and flexibility of organizations are two indicators that have the lowest positions in the ranking and it can be interpreted that provision of these two indexes is expensive, timeconsuming and are at the lowest amount probability regarding the possibility.

\section{Conclusion and Discussion}

Crisis management is an applied science that is searching some means to prevent occurrence of crises by systematic observation of crises and analysis of them. Alternatively, if the crises happen, we need to be prepared for quick relief and recovery in order to reduce the effects of crisis. Nowadays, the main weaknesses of crisis management are the lack of coordination and cooperation of organizations, lack of comprehensive rules and regulations, inadequate distribution of existing laws and regulations, and the limited financial resources. Traditional view to crisis management believed that crisis management means extinguishing fire; it means that crisis managers wait for deterioration of affairs; after the destruction, they try to limit the damages caused by the destruction. However, this view has recently changed. According to the recent meaning, a collection of plans and practical programs must be set within the organizations to deal with possible future developments. In addition, managers wonder about the possible future events and should be ready for dealing with unpredicted events. Therefore, crisis 
management emphasizes on the need of disciplined anticipation and getting ready to deal with those internal and external issues that will seriously threaten fame, reputation and/ or life of organization. It must be considered that crisis management is different from public relation management. Public relation manager tries to show a good face of organization, while crisis manager tries to maintain the organization in a good condition at the time of crisis. Crisis management is considered as a scientific discipline, generally in the field of strategic management and specifically is linked to issues of strategic control. Organizational crisis management is an organized process through which the organization tries to identify and predict potential crisis. Then, they try to take preventive measures to minimize the effects. In order to implement crisis management in organization, in the present study, effective indicators on crisis management enhancement have been studied. The results prepare a ranked list of indexes for managers that can try to implement and run the indexes of crisis management in accordance with them.

\section{References}

Amiri, M., Ayazi, S. A., Olfat, L., \& Moradi, J. S. (2011). Group decision making process for supplier selection with VIKOR under fuzzy circumstance case study: an Iranian car parts supplier. International Bulletin of Business Administration, 10(6), 66-75.

Booth, S. A. (2015). Crisis management strategy: Competition and change in modern enterprises. Routledge.

Fahmideh Modami, M. \& Hatami Nejad, H. (2014). Identifying indicators of crisis management in city with the prevention and readiness approach, a case study in Mashhad, crisis the second national conference of crisis management and HSE on Lifeline, industry and urban management, Tehran, Permanent Secretariat of the National Disaster Management Conference.

Fink, S. (1986). Crisis management: Planning for the inevitable. New York, NY: American Management Association.

Hwang, C. L., \& Yoon, K. (1981). Multiple attribute decision making, in lecture notes in economics and mathematical systems 186.

Kazemi, A. (2013). Organizational crisis management. European Online Journal of Natural and Social Sciences, 2(3), 1412-1422.

Mitroff, I. I. (2004). Crisis leadership: Planning for the unthinkable. John Wiley \& Sons Inc.

Moradi, J., Ghorbanzad, Y., \& Beig, M. (2012). Identifying and prioritizing innovation criteria of projects in science and technology parks using fuzzy VIKOR. Management Science Letters, 2(2), 587-596.

Parsons, W. (1996). Crisis management. Career Development International,1(5), 26-28.

Pearson, C. M., \& Clair, J. A. (1998). Reframing crisis management.Academy of management review, 23(1), 59-76.

Pourmousavi, S.M, Eghbal M., \& Khoshkhan J. (2015). Evaluation of implementation disaster management indicators in the detailed plan (Case study: 20th municipal district of Tehran). Journal of Spatial Analysis Environmental Hazards, 2 (2), 17-31

Wang, J., Hutchins, H. M. \& Garavan, T. N. (2009). Exploring the strategic role of human resource development in organizational crisis management. Human Resource Development Review. Doi: $10.1177 / 1534484308330018$

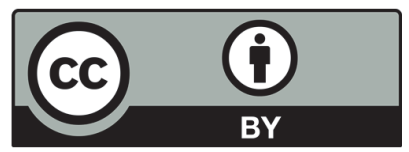

(C) 2016 by the authors; licensee Growing Science, Canada. This is an open access article distributed under the terms and conditions of the Creative Commons Attribution (CC-BY) license (http://creativecommons.org/licenses/by/4.0/). 